\title{
Experimental Study on Vibration Reduction Characteristics of Gear Shafts Based on ISFD Installation Position
}

\author{
Kaihua Lu, Lidong He, and Yipeng Zhang \\ Beijing Key Laboratory of Health Monitoring and Self-Recovery for High-End Mechanical Equipment, \\ Beijing University of Chemical Technology, Beijing 100029, China \\ Correspondence should be addressed to Lidong He; 1963he@163.com
}

Received 25 August 2017; Accepted 28 November 2017; Published 19 December 2017

Academic Editor: Marc Thomas

Copyright (C) 2017 Kaihua Lu et al. This is an open access article distributed under the Creative Commons Attribution License, which permits unrestricted use, distribution, and reproduction in any medium, provided the original work is properly cited.

\begin{abstract}
A novel type of integral squeeze film damper (ISFD) is proposed to reduce and isolate vibration excitations of the gear system through bearing to the foundation. Four ISFD designs were tested experimentally with an open first-grade spur gear system. Vibration reduction characteristics were experimentally studied at different speeds for cases where ISFD elastic damping supports were simultaneously installed on the driving and driven shafts, installed on the driven shaft, or only installed on the driving shaft. Experimental results show that the ISFD elastic damping support can effectively reduce shock vibration of the gear system. Additionally, resonant modulation in gear shafts caused by meshing impact was significantly reduced. Different vibration amplitudes of gear shafts with ISFD installed only on driven or driving shafts were compared. Results indicated that vibration reduction is better when ISFD is only installed on the driven shaft than on the driving shaft.
\end{abstract}

\section{Introduction}

Gear mechanisms are among the most widely used power equipment and motion transmission devices in machines, with applications in aerospace, shipping, machining, petrochemical, and energy industries. It is important to note that working condition of a gear system is extremely complex. Typically, the primary motor introduces an external load; however internal incentives introduced by time-varying meshing stiffness and gear error become the main source of vibration in the transmission system. This vibration would affect overall performance of the equipment [1]. Larger vibration noise will be produced when there are preexisting manufacturing and installation errors or in cases when operating conditions are strict. Excessive vibration would result in fatigue failure of the mechanical structure and in turn affect production safety. Vibration characteristics of the gear system are relatively complex and can be categorized mainly into two pulses. These two pulses are meshing frequency with its high harmonics and rotating frequency with its low-order harmonics [2].

Vibration control of a gear system can be broadly classified in two methods. In the first method, exciting force is reduced to control and effectively reduce the vibration source. In general, first structural parameters of the gears should be adjusted to improve their meshing. A damping material in the tooth or wheel of the gears can aid in avoiding resonance of the gear system. In the second approach, source of vibration can be controlled to isolate or reduce transmission of the vibration. Therefore, some local vibration isolation measures can be added in appropriate locations in the gear system, which would reduce transfer of meshing vibration in the gear system to the whole structure through the bearings [3]. Research reported in literature by both domestic and international research groups has been primarily focused on the first method. This method can be divided into active design and passive vibration suppression [4]. Active design takes gear dynamics and vibration theory into perspective to reduce vibration by optimizing design parameters, modifying gear tooth, and improving manufacturing accuracy [5]. Friction dampers (damping ring and damping plug) and viscoelastic dampers (free damping layer and constrained damping layer) used in passive vibration suppression have some limitations. For example, use of damping ring and damping plug is confined to lower natural frequency vibration components and is not appropriate for broadband vibration suppression 
$[6,7]$. Vibration suppression effect of viscoelastic material is greatly influenced by thickness of the damping layer.

Squeeze film damper (SFD) and bearing are used cooperatively in turbomachinery such as the compressors, turbines, and generators to solve problems associated with vibration and stability of the rotor. SFD allows the support structure to simultaneously have a lower stiffness and higher damping. Low support stiffness reduces dynamic loads transmitted through the bearings to nonrotating structures. This helps in prolonging bearing life and minimizing structural vibration [8]. In a gear compressor, SFD has been used to reduce and isolate meshing incentives of a gear. Chen et al. [9] established a calculation model for the gear system with SFD support and analyzed bend torsion coupling vibration of the system under unbalanced excitation. Calculation results show that SFD can significantly reduce mode dominated by radial vibration. Additionally. It was observed that mode dominated by torsional vibration was sensitive to meshing damping of the gear system. Chen et al. [10] investigated stability and complex dynamic characteristics of a nonlinear gear system under unbalanced incentive with one SFD support. Results showed that unstable periodic response could be simultaneously accompanied with quasiperiodicity and chaotic motion within the frequency response range. Chang-Jian [11] analyzed dynamic behavior of the gear-bearing system with one porous squeeze film damper (PSFD) support and the results show that PSFD can improve dynamic stability of the gear-bearing system.

Specific structure of an integral squeeze film damper (ISFD) allows many problems in traditional squeeze film dampers to be resolved. Problems such as nonlinear oil film, complex structure, large occupation space, difficult assembling, high-accumulated error, and nonlinear change of the stiffness and damping characteristics can be solved. ISFD has been applied in many turbine machines such as compressors, turbines, and engines [12, 13]. However, there are only few research reports in literature, which have discussed use of ISFD to reduce and isolate gear meshing excitation to suppress vibration of the gear system.

In this paper, a novel method to control vibration of gear system is proposed. This is achieved by isolating gear meshing vibration, to reduce vibration transmitted to the foundation through the bearings. A new ISFD was designed and vibration suppression characteristics of gear system were studied through experiments. Four sets of experimental ISFD elastic damping support structures were processed and an open first-grade spur gear system was built. Vibration reduction characteristics of gear shafts were studied with ISFD installed on both driving shaft and driven shaft, only installed on the driven shaft, or only installed on the driving shaft at different speeds.

\section{Vibration Model and Analysis of Gear System}

Here, vibration model of a simple transmission gear system is first established. The intermeshing gear pair is simplified as a vibration source with a concentrated mass and the gearbox is simplified as another excited concentrated mass. Bearings

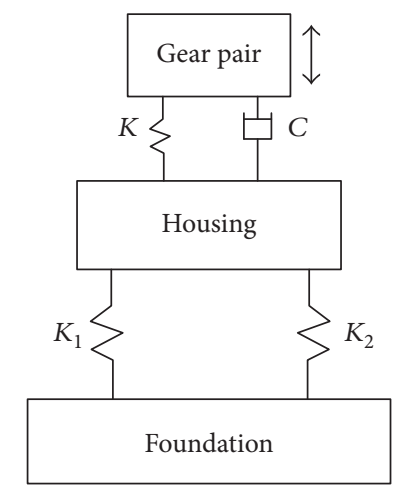

FIGURE 1: Vibration of gear system.

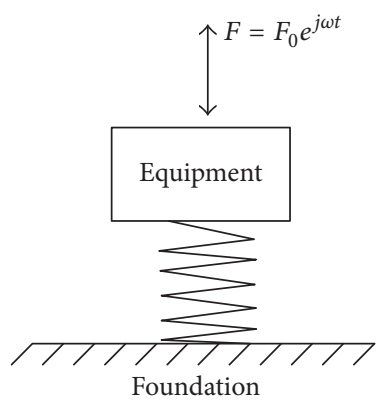

FIGURE 2: Single-degree-of-freedom vibration isolation system.

between the gear and housing are regarded as springs with a certain stiffness and damping. Generally, front and rear ends of the gearbox are supported by the engine and main shaft on the base. Concentrated mass of the gearbox is elastically connected with the foundation and vibration model of the whole gear system can be simplified as shown in Figure 1 [3].

According to vibration isolation theory [14], in order to reduce vibration response of the gear system, radial stiffness of the bearing should be decreased and vibration damping of the bearing should be increased. In other words, stiffness coefficient $K$ is decreased, damping coefficient $C$ is increased, and natural frequency of the system is decreased. As a result, vibration transmission coefficient of the system is decreased.

In this experiment, vibration of the bearing block is considered as the evaluation index. Model of a single-degreeof-freedom vibration isolation system for a gear pair bearing is shown in Figure 2. Equation of motion for the system is given by

$$
M \ddot{x}+C \dot{x}+K x=F_{0} e^{j \omega t},
$$

where $M, K, C$ denote mass, stiffness, and damping of the vibration isolation system, respectively. The vibration displacement of the system is given by

$$
x_{0}=\left|\frac{F_{0}}{K} \frac{1}{\left(1-z^{2}+j 2 \zeta z\right)}\right| \text {, }
$$

where $\omega_{0}=\sqrt{K / M}$ denotes natural frequency of the system, $z=\omega / \omega_{0}$ is frequency ratio, and $\zeta=C /(2 \sqrt{K M})$ denotes damping coefficient. Disturbance force is transmitted to the 
foundation through the vibration isolation spring $K$, and disturbance force on the foundation is calculated as

$$
P=C \dot{x}+K x .
$$

Its amplitude is shown as

$$
P_{0}=\left|j \omega C x_{0}+K x_{0}\right| .
$$

Vibration transmission coefficient of the system is expressed as

$$
\begin{aligned}
T_{f} & =\left|\frac{P_{0}}{F_{0}}\right|=\left|\frac{1}{K} \frac{j \omega C+K}{\left(1-z^{2}+j 2 \zeta z\right)}\right| \\
& =\frac{\sqrt{1+(2 \zeta z)^{2}}}{\sqrt{\left(1-z^{2}\right)^{2}+(2 \zeta z)^{2}}} .
\end{aligned}
$$

As seen from (5), when vibration disturbance frequency $\omega$ is significantly larger than natural frequency of the system $\omega_{0}$, vibration transmission coefficient is less than 1 and system has a vibration isolation effect. Higher vibration disturbance frequency compared to natural frequency of the system results in a lower vibration transmission coefficient. As a result, vibration isolation effect is improved. Vibration frequency and its higher harmonics of gear meshing are high frequency components; these are generally significantly higher than natural frequency of the gear shafts. Therefore, these vibration isolation measures are effective. Disturbance frequency may not be completely eliminated in a certain frequency band, especially when the equipment starts or shuts down. This disturbance has a broad bandwidth. So, vibration isolation system must have an appropriate damping to avoid system resonance.

\section{Integral Squeeze Film Damper}

3.1. Structural Features. ISFD differs from other dampers in that it is an integral bearing damper made using wire electric discharge machine (EDM) technology. This allows the bearing support to have a better damping effect for the rotor system. The integral design provides improvement in machining, thereby allowing precise concentricity, stiffness, and rotor position. ISFD designed for experiments used in this work is shown in Figure 3. The structure consists of an outer rim and inner rim. The outer rim and inner rim are connected by a fixed number of S-shaped spring structures. S-shaped springs allow pressure to be distributed evenly. Radial static stiffness of the bearing support system is determined by these S-shaped elastic structures. Clearance between the S-shaped springs forms squeeze films, thereby providing damping required by the system. Displacement cloud of the experimental ISFD under the loading conditions is shown in Figure 4.

Figure 5 shows mechanical models of the traditional bearing support system and ISFD bearing support system. Comparing the two models, it can be seen that stiffness of the ISFD structure is several orders of magnitude lower than that of the bearing. Vibration deformation during transmission is

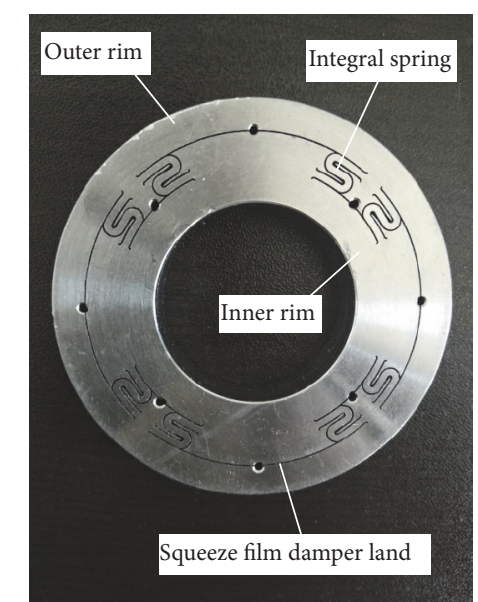

FIgURE 3: Experimental S-type elastomer.

mainly concentrated on the elastic support, which can absorb some vibration energy. In addition, the oil film damping provided by ISFD can dissipate vibration energy.

3.2. Energy Dissipation Mechanism. Energy dissipation mechanism of the conventional squeeze film damper (SFD) is based on generating fluid pressure $\Delta p$ by squeezing the oil film. This promotes movement of lubricating oil along the circumference. Flow friction due to circumferential motion of the fluid produces damping to dissipate energy. There is obviously significant nonlinearity as a result of this approach. Stiffness and damping in the new ISFD structure are relatively independent, such that stiffness and damping in the support system do not have a direct relationship, that is, elastic damping structure decoupling ability. As a result, ISFD can provide a relatively low stiffness through the S-type structure while providing a greater damping in the squeeze film damper, effectively increasing damping ratio of the system $[15,16]$.

\section{Experimental Setup}

4.1. Support Structure. In order to study vibration reduction characteristics of ISFD for gear shafts, two kinds of support structures were designed for use with the laboratory rotor: rigid support and ISFD elastic damping support. Specific structure for both these structures is shown in Figure 6. The rigid support is made up of a bearing block, a sleeve, and a rolling bearing, whereas the ISFD elastic damping support consists of a bearing block, an S-type elastomer, a rolling bearing, O-type rubber rings, and sealed-end covers. Figure 6(c) is a bearing cover with O-type rubber rings, on which there are a grease hole and oil drain hole. The bigger sized $\mathrm{O}$ type rubber ring provides a static seal between the bearing cover and bearing block, while the smaller size O-type rubber ring guarantees a dynamic seal between the bearing cover and shaft. Vibration reduction characteristics of ISFD are studied by comparing vibration amplitude of the two types of supported gear systems. 
A: static structural

Directional deformation

Type: directional deformation ( $x$-axis)

Unit: $\mathrm{mm}$

Coordinate system

Time: 1

2017/4/5 20:38

0.18168 Max

0.16122
0.14076

0.12029

0.099832

0.07937

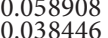

0.017984

$-0.002478 \mathrm{Min}$

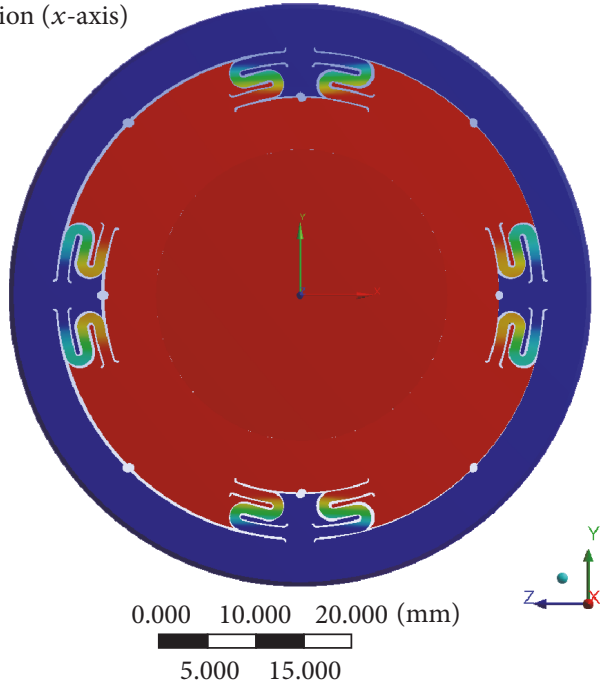

(a) $X$ direction

A: Static structural

Directional deformation

Type: directional deformation ( $y$-axis)

Unit: $\mathrm{mm}$

Coordinate system

Time: 1

2017/4/5 20:40

0.18205 Max
0.16155
0.14105
0.12056
0.10006
0.079563
0.059065
0.038568
0.01807
-0.002427 Min

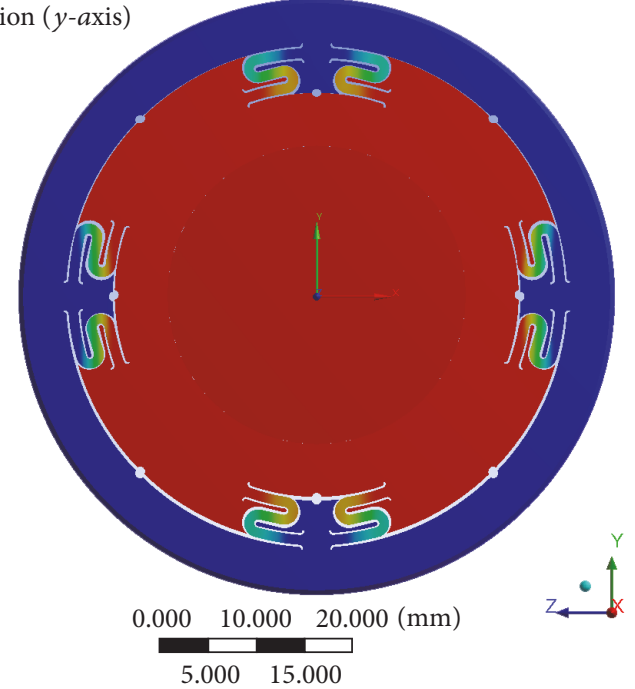

(b) $Y$ direction

FIGURE 4: Displacement cloud of ISFD under a loading of $6000 \mathrm{~N}$.

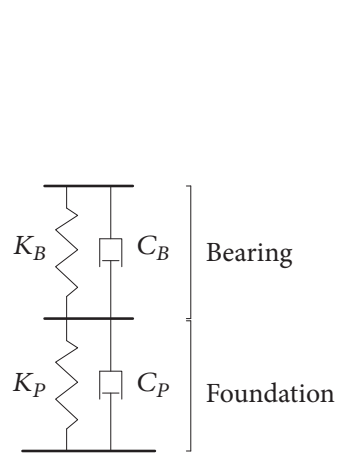

(a) Traditional bearing support system

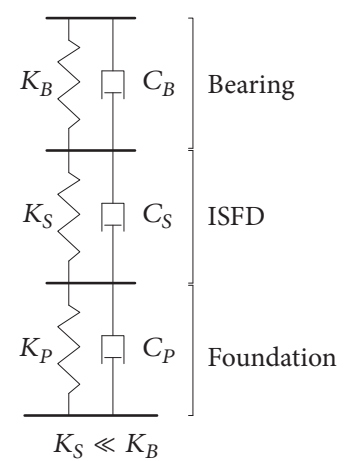

(b) ISFD bearing support system

Figure 5: Mechanical models of traditional bearing support system and ISFD bearing support system. 


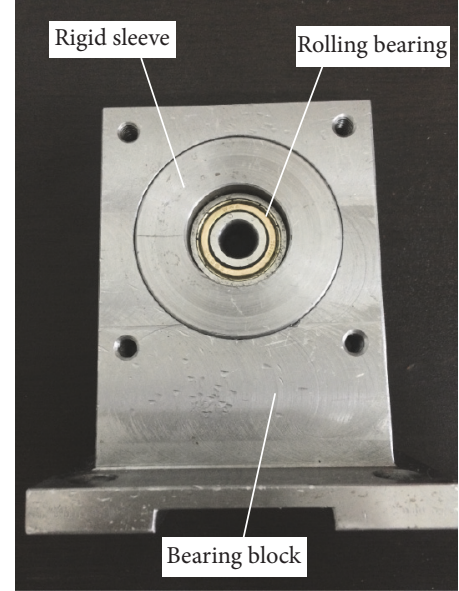

(a) Rigid support

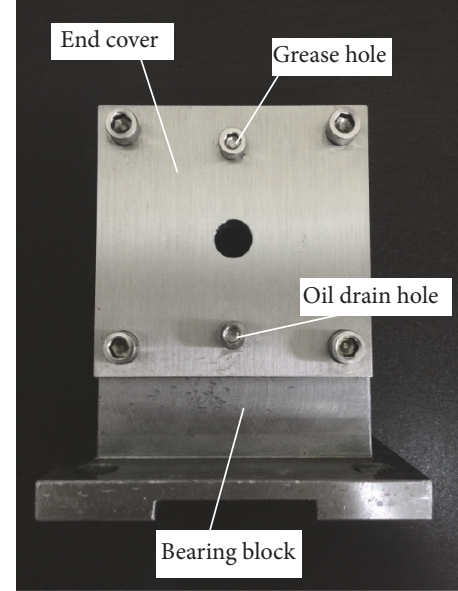

(b) ISFD elastic damping support

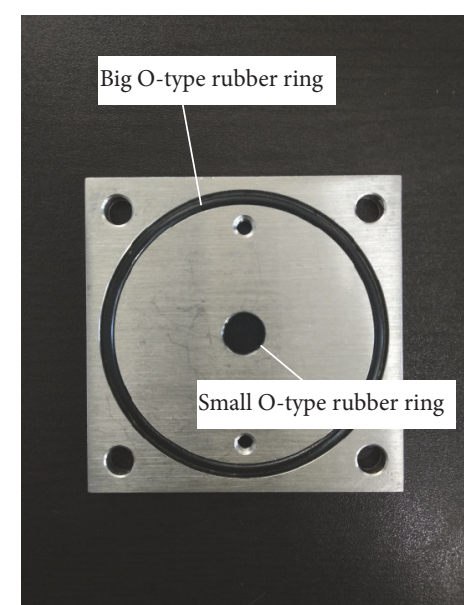

(c) Bearing cover with O-type rubber rings

FIGURE 6: Two kinds of experimental support and bearing cover used in the elastic damping support.

(1) (2) (3)

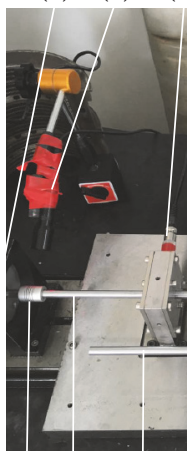

(13) (12)
(3)

(4)

(5)
(1) Motor
(2) Photoelectric sensors
(3) Acceleration sensor 1
(4) Acquisition system LC-8008
(5) Driving gear
(6) Computer
(7) ISFD elastic damping support
(8) Motor speed controller
(9) Driven gear
(10) Acceleration sensor 2
(11) Driven shaft
(12) Driving shaft
(13) Flexible coupling

Figure 7: Test apparatus.

4.2. Experimental Parameters. The experimental gear transmission system is shown in Figure 7. The gear system is composed of involute spur gears on the driving and driven shafts. Parameters of the gear pair are listed in Table 1. Diameter of two shafts is $10 \mathrm{~mm}$. Driving and driven shaft spans are $320 \mathrm{~mm}$ and $180 \mathrm{~mm}$, respectively. The driving shaft is driven by a permanent magnet DC servomotor. By adjusting the speed controller output speed can be controlled in the
TAble 1: Parameters of the gear pair.

\begin{tabular}{lc}
\hline Gear parameters & Value \\
\hline Number of teeth of the driving gear & 30 \\
Number of teeth of the driven gear & 20 \\
Gear ratio & $2 / 3$ \\
Gear modulus $(\mathrm{mm})$ & 3 \\
Pressure angle $\left(^{\circ}\right)$ & 20 \\
Tooth thickness of the driven gear $(\mathrm{mm})$ & 30 \\
Tooth thickness of the driving gear $(\mathrm{mm})$ & 28 \\
Theoretical center distance $(\mathrm{mm})$ & 75 \\
\hline
\end{tabular}

range of $0-10000 \mathrm{r} / \mathrm{min}$. Using the drip method during the experiments lubricates the gear pair.

During the experiment, the LC-8008 vibration monitoring and diagnosis system was used for vibration test. This system included 8 input channels, which can collect, store, and analyze vibration in time and frequency domains along with other real-time data during transmission of gear system. Acceleration sensor adsorbed on the driving and driven bearing blocks is used to collect the vibration signal. Acceleration sensor 1 measures vibration in the horizontal direction of the driving bearing block, whereas vibration in the horizontal direction of the driven bearing block is measured by acceleration sensor 2. Photoelectric sensors collect rotating speed.

\section{Results and Discussion}

5.1. Simultaneous Vibration Reduction Using ISFD Elastic Damping Supports Installed on Two Shafts. Acceleration in both time and frequency domain for bearing blocks is collected when gear shafts are installed with rigid support and ISFD elastic damping support. Rotating speed of the driving shaft was measured as $n_{1}=300 \sim 1600 \mathrm{r} / \mathrm{min}$ by adjusting the speed controller. Next, rotating speed of the driven shaft was determined to be $n_{2}=n_{1} / i=450 \sim 2400 \mathrm{r} / \mathrm{min}$. Frequency was 


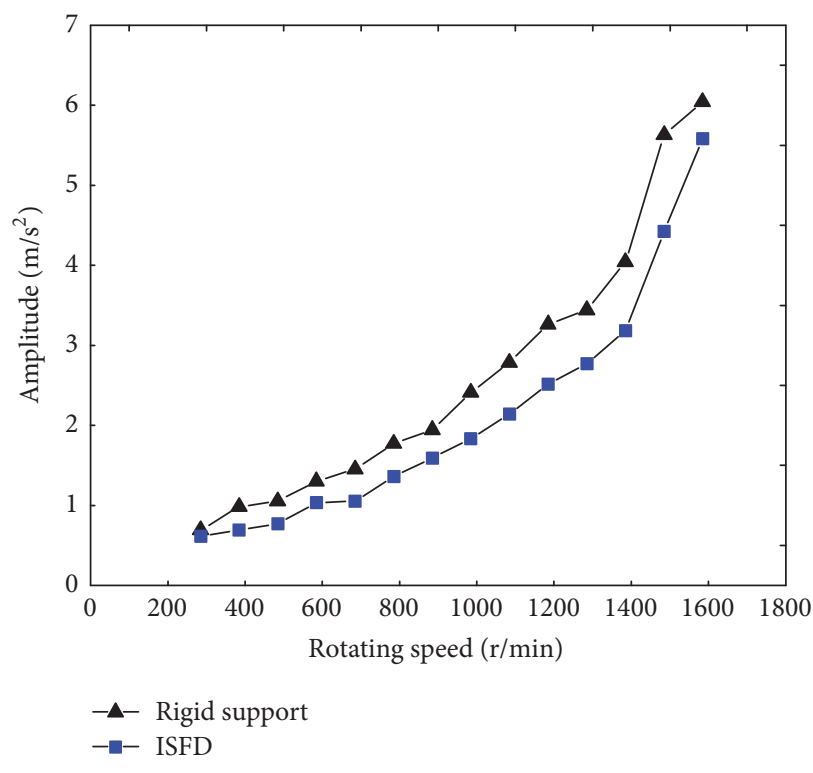

(a) Comparison of vibration of the driving shaft

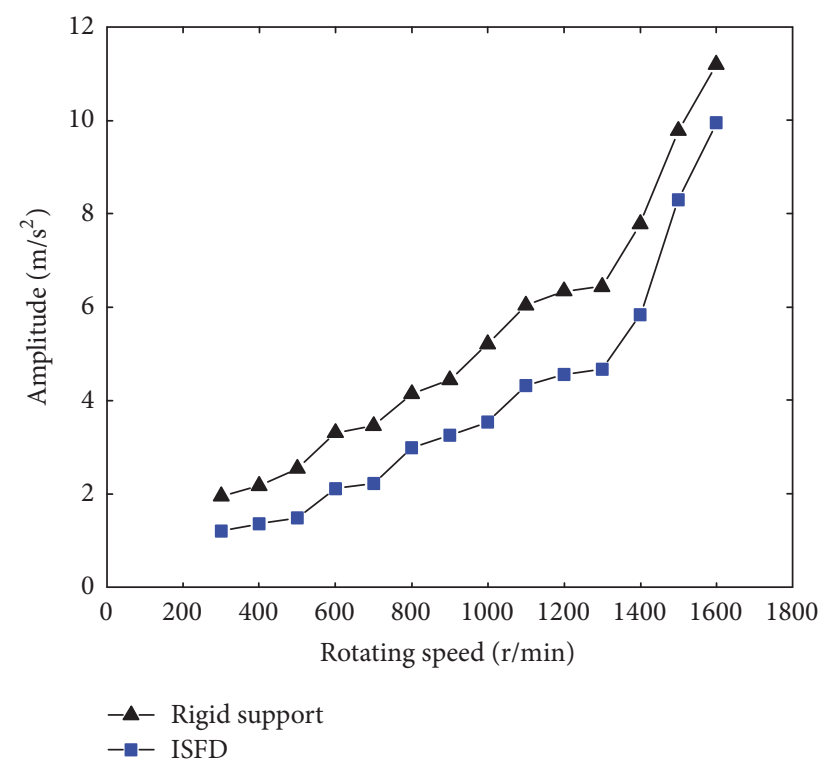

(b) Comparison of vibration of the driven shaft

FIGURE 8: Curve of acceleration amplitude at measured points versus rotating speed with different supports.

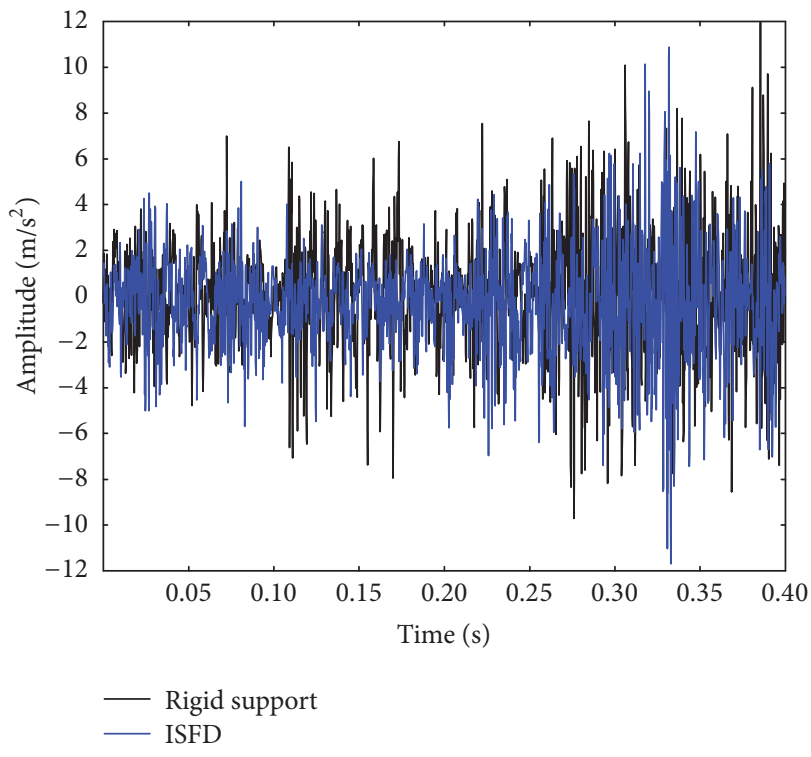

(a) Comparison of time domain waveform of driving shaft

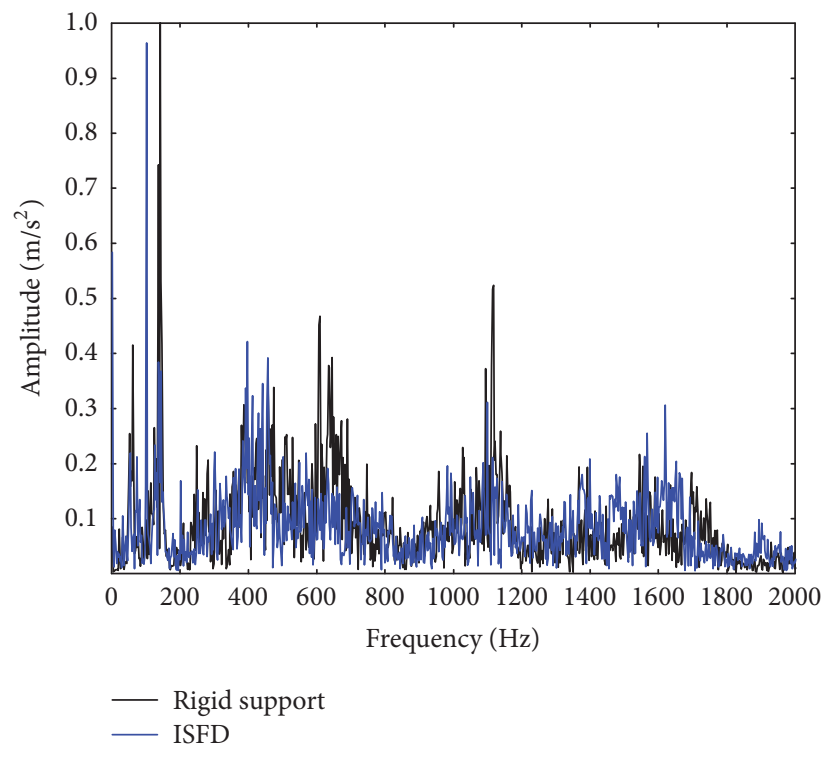

(b) Comparison of frequency spectrum of driving shaft

FIGURE 9: Comparison of vibration of driving shaft measuring point.

determined as $2 \mathrm{kHz}$ with a total number of 2048 sampling points and was analyzed using the data acquisition system LC-8008. The data is recorded every $100 \mathrm{r} / \mathrm{min}$. Figure 8 shows acceleration amplitude of gear shafts as a function of rotating speed during the process of speeding up.

As seen from experimental results in Figure 8, vibration value at measured point of a gear shaft at each rotating speed is reduced when support is changed from rigid support to ISFD elastic damping support. Within the experimental rotating speed range, maximum amplitude of vibration reduction for the driving and driven shafts in horizontal direction is $23.6 \%$ and $41.3 \%$, respectively.
Due to space limitations, time domain and frequency spectrum for each measurement point vibration acceleration is analyzed when the rotating speed of the driving shaft is $1200 \mathrm{r} / \mathrm{min}$. Time domain and frequency spectrum at measured points of two shafts in horizontal direction are shown in Figures 9 and 10, respectively, for gear shafts with rigid support and ISFD elastic damping support.

From time domain waveforms shown in Figures 9(a) and 10(a), it can be seen that there is a modulation phenomenon seen in the waveforms. Besides, there is an obvious impact vibration seen in the gear meshing transmission process, and a periodic phenomenon is not obvious. It is known from 


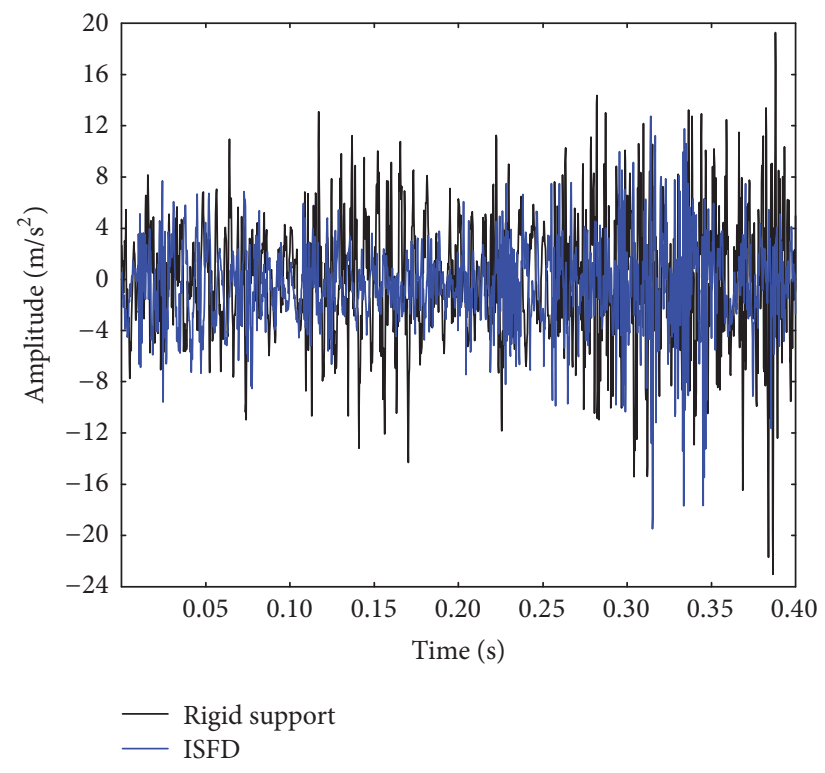

(a) Comparison of time domain waveform of driven shaft

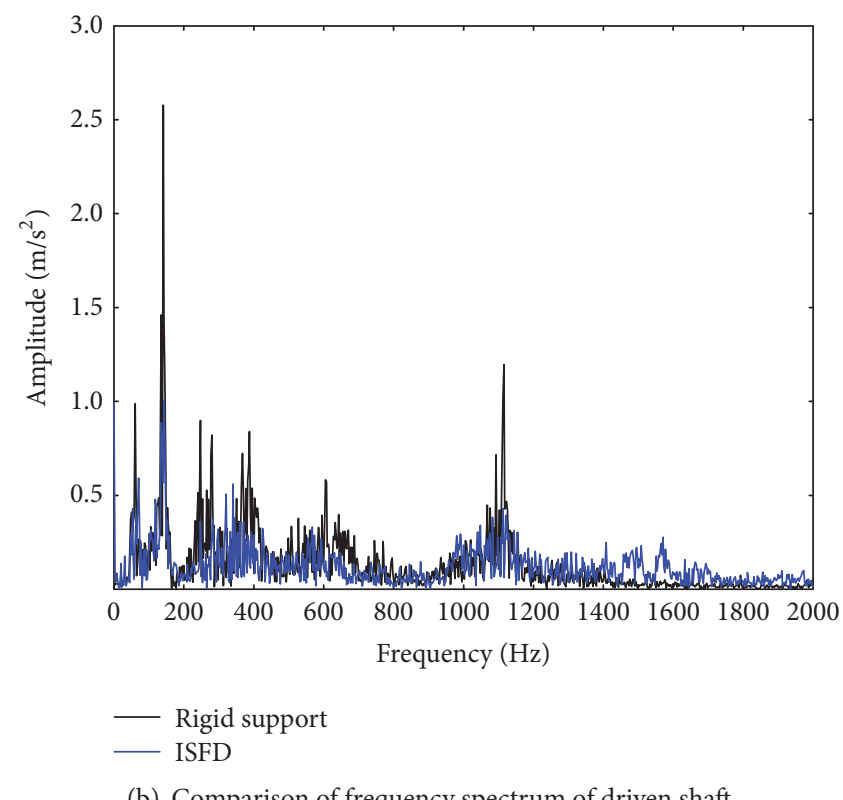

(b) Comparison of frequency spectrum of driven shaft

FIGURE 10: Comparison of vibration of driven shaft measuring point.

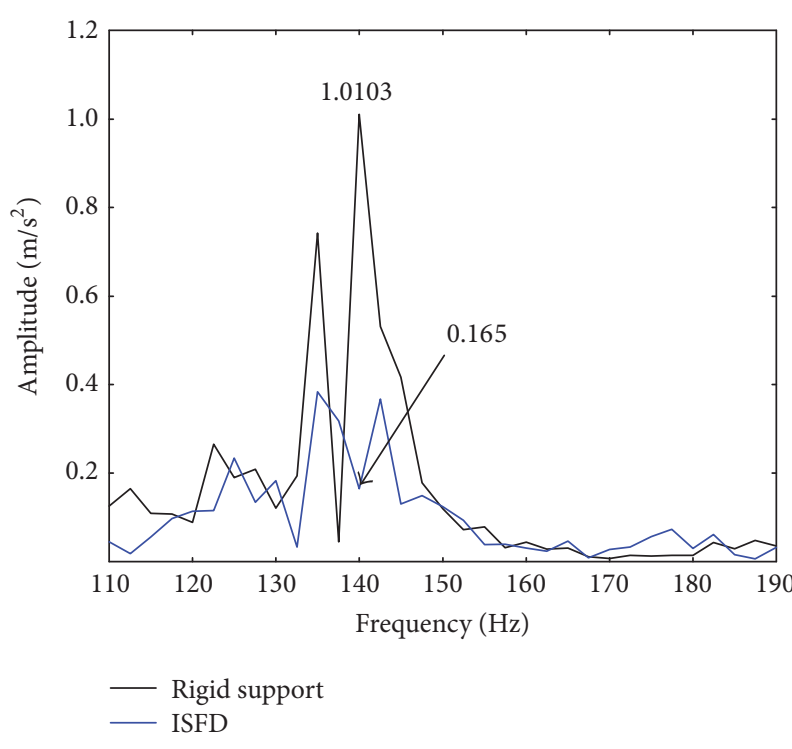

(a) Frequency spectrum of driving shaft

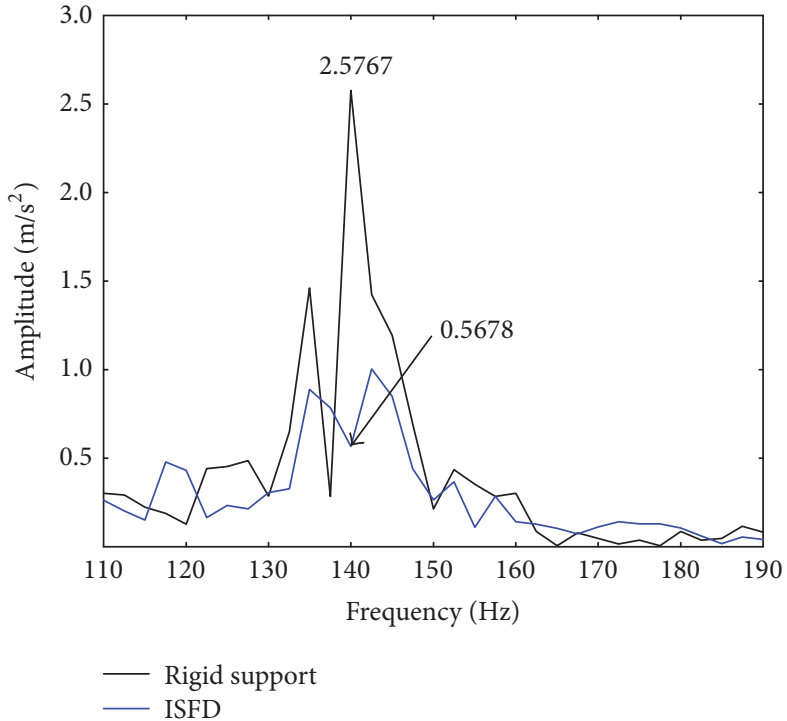

(b) Frequency spectrum of driven shaft

FIGURE 11: Comparison of data in the range of 110 190 Hz.

the transmission parameters that meshing frequency of the gear pair is $f=f_{1} Z_{1}=f_{2} Z_{2}=600 \mathrm{~Hz}$. As seen from the frequency spectrum in Figures 9(b) and 10(b), multiple frequency components exist in the spectrums. Vibration value near meshing frequency is relatively large, and a wide sideband is observed. Otherwise, vibration values observed in the vicinity of $140 \mathrm{~Hz}$ and $1100 \mathrm{~Hz}$ are also relatively large. According to theory of vibration [17], this result indicates resonance of the gearbox and gear shafts.

As seen from the time domain waveforms in Figures 9(a) and 10(a), modulation phenomenon in time domain waveform has been improved and shock vibration has been reduced in ISFD elastic damping support compared to rigid support. Peak value of acceleration for driving shaft is reduced from $3.51 \mathrm{~m} / \mathrm{s}^{2}$ to $2.76 \mathrm{~m} / \mathrm{s}^{2}$, a decrease of $21.4 \%$. Acceleration peak for driven shaft is reduced from $6.34 \mathrm{~m} / \mathrm{s}^{2}$ to $4.56 \mathrm{~m} / \mathrm{s}^{2}$, a decrease of $28.1 \%$.

From the frequency spectrum in Figures 9(b) and 10(b), it can be concluded that frequency components with relatively large vibration amplitude are significantly attenuated, when support is changed from rigid support to ISFD elastic damping support. In order to carry out an unambiguous comparison, here frequency spectrum ranges between 110 $190 \mathrm{~Hz}, 560 \sim 640 \mathrm{~Hz}$, and $1060 \sim 1140 \mathrm{~Hz}$ are shown. Figures 11-13 show correlation data corresponding to these three frequency ranges. 


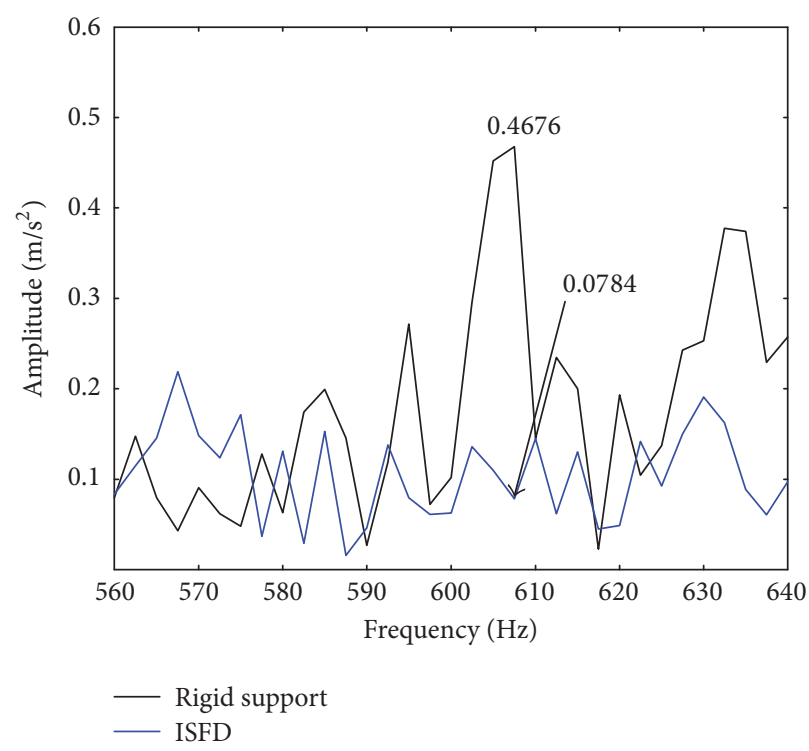

(a) Frequency spectrum of driving shaft

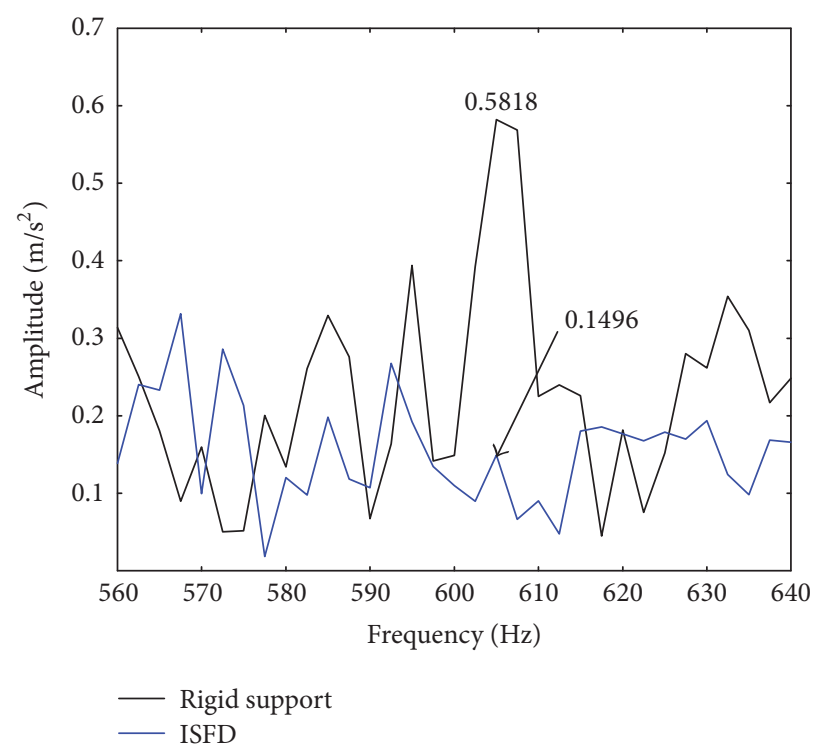

(b) Frequency spectrum of driven shaft

FIgURE 12: Comparison of data in the range of 560 640 Hz.

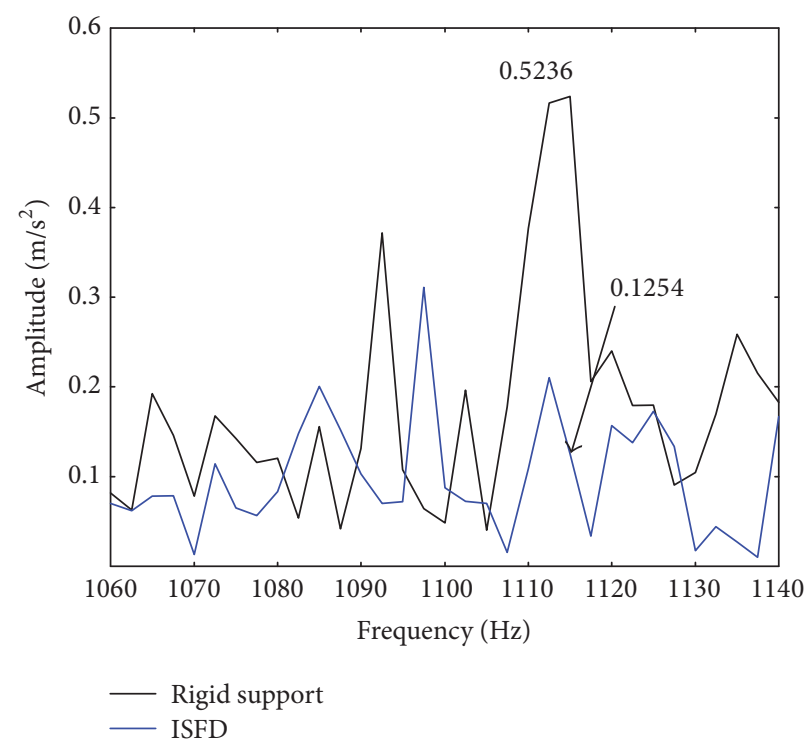

(a) Frequency spectrum of driving shaft

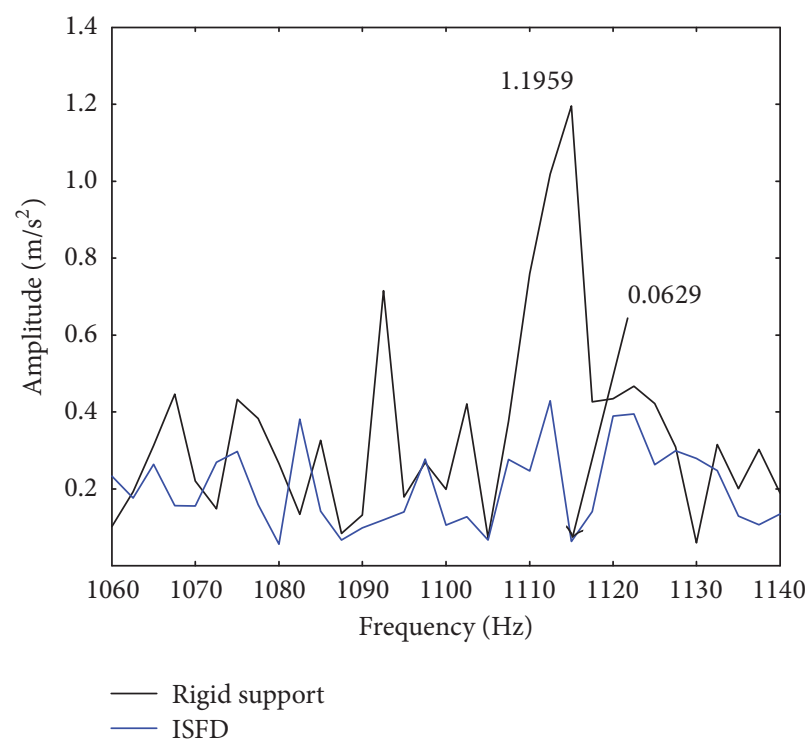

(b) Frequency spectrum of driven shaft

FIGURE 13: Comparison of data in the range of 1060 1140 Hz.

Tables 2-3 show vibration reduction for the measured points of the driving and driven shafts in the vicinity of $140 \mathrm{~Hz}, 600 \mathrm{~Hz}$, and $1100 \mathrm{~Hz}$. It can be seen that the vibration reduction for all these three frequency points is above $50 \%$, and resonance modulation of the gear shaft is obviously improved.

5.2. Vibration Reduction for ISFD Elastic Damping Supports Installed on a Single Shaft. In order to study control of gear shaft vibration when only ISFD is installed on a single shaft, vibration of gear shafts is measured under two conditions. First, when ISFD is installed on driven shaft, rigid support is installed on driving shaft and second when ISFD is installed
TABLE 2: Vibration reduction with different supports (driving shaft).

\begin{tabular}{lccc}
\hline $\begin{array}{l}\text { Frequency } \\
(\mathrm{Hz})\end{array}$ & \multicolumn{4}{c}{$\begin{array}{c}\text { Acceleration amplitude of driving shaft } \\
\text { measuring point }\left(\mathrm{m} / \mathrm{s}^{2}\right)\end{array}$} \\
\hline 140 & Rigid support & ISFD support & Decreasing (\%) \\
607.5 & 1.0103 & 0.165 & 83.7 \\
1115 & 0.4676 & 0.0784 & 83.2 \\
\hline
\end{tabular}

on driving shaft, rigid support is installed on driven shaft. Rotating speed of driving shaft is set as $n_{1}=300 \sim 1600 \mathrm{r} / \mathrm{min}$. Vibration measurement results under these two conditions are shown in Figure 14. 


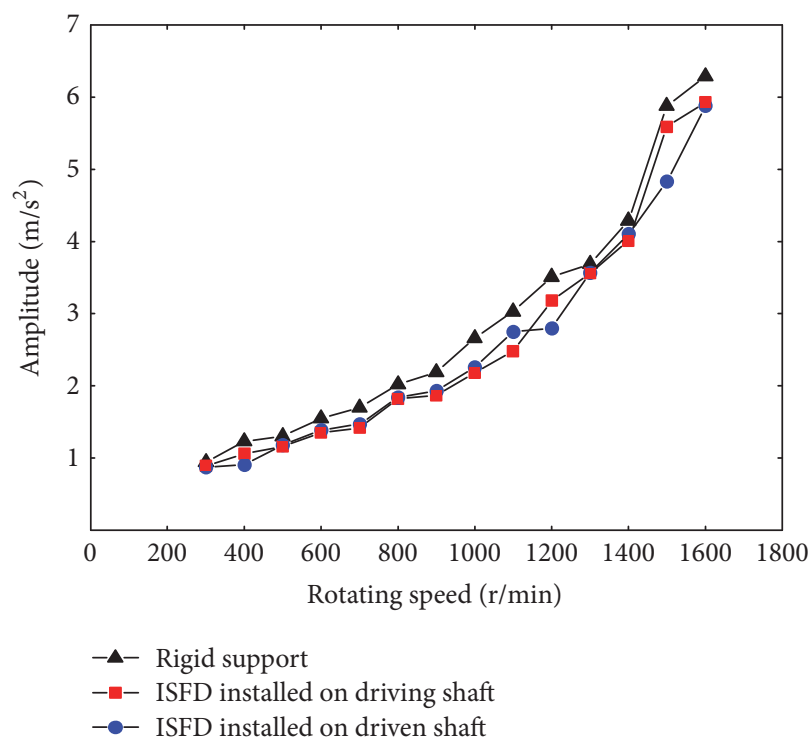

(a) Comparison of vibration of driving shaft

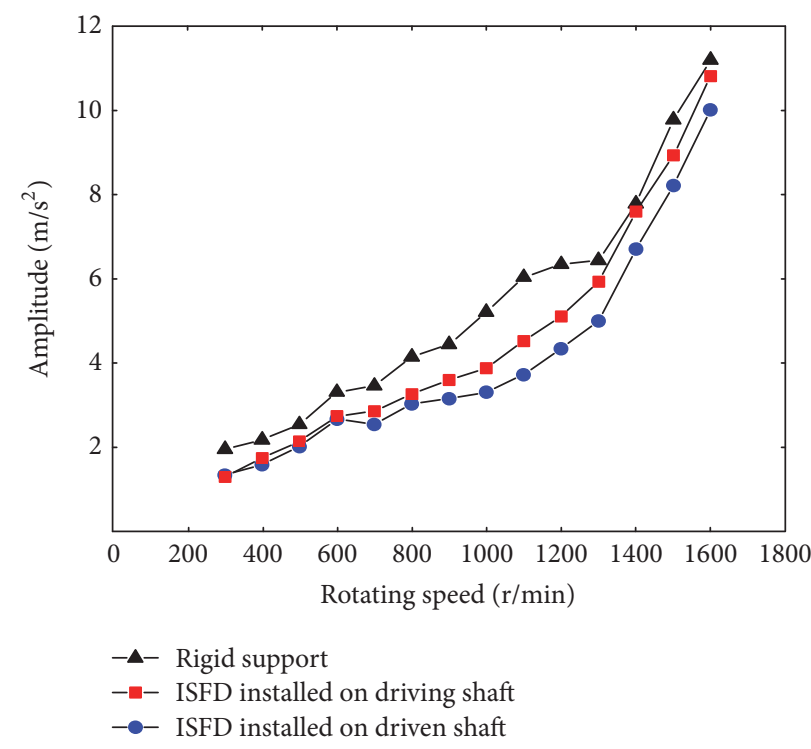

(b) Comparison of vibration of driven shaft

FIGURE 14: Comparison of vibration under two conditions.

TABLE 3: Vibration reduction with different supports (driven shaft).

\begin{tabular}{lccc}
\hline $\begin{array}{l}\text { Frequency } \\
(\mathrm{Hz})\end{array}$ & \multicolumn{3}{c}{$\begin{array}{c}\text { Acceleration amplitude of driven shaft } \\
\text { measuring point }\left(\mathrm{m} / \mathrm{s}^{2}\right)\end{array}$} \\
& Rigid support & ISFD support & Decreasing (\%) \\
\hline 140 & 2.5767 & 0.5678 & 78.0 \\
605 & 0.5818 & 0.1496 & 74.3 \\
1115 & 1.1959 & 0.0629 & 94.7 \\
\hline
\end{tabular}

TABle 4: Average amplitude of vibration reduction under two conditions.

\begin{tabular}{lcc}
\hline Decreasing (\%) & $\begin{array}{c}\text { ISFD installed on } \\
\text { driving shaft }\end{array}$ & $\begin{array}{c}\text { ISFD installed on } \\
\text { driven shaft }\end{array}$ \\
\hline Driving shaft & 10.7 & 11.7 \\
Driven shaft & 16.9 & 25.1 \\
\hline
\end{tabular}

From the measured results in Figure 14, it can be observed that vibration of gear shafts is reduced in all cases; that is, vibration is reduced irrespective of ISFD support location, on either the driving or driven shafts. Table 4 lists average amplitude of vibration reduction under two conditions.

As seen from Table 4, for the driving shaft, average amplitude of vibration reduction between the two conditions has no significant difference. For driven shaft, amplitude of vibration reduction is larger when ISFD is installed on driven shaft. In addition, it can be concluded that the vibration reduction effect is better for cases when ISFD is only installed on the driven shaft compared to installation on driving shaft. From the vibration measuring results, it can be seen that vibration of driven shaft is larger compared to driving shaft. Therefore, if ISFD can be installed only on a single shaft with the aim of maximum vibration reduction, then installation should be carried out on the shaft with the larger vibration.

\section{Conclusion}

ISFD elastic damping support can effectively reduce transmission of gear meshing excitation effectively. No additional changes need to be made to the equipment and foundation to achieve good vibration control. From the experimental results, the following conclusions can be reached:

(1) ISFD support can reduce shock vibration of the gear system with excellent damping vibration attenuation characteristics.

(2) The ISFD support structure effectively reduced vibration in gear shafts and maximum amplitude of vibration reduction reached $41.3 \%$.

(3) The proposed ISFD support structure reduced resonance modulation caused by meshing shock in gear shafts.

(4) Comparison of vibration reduction characteristics at different rotating speeds revealed that vibration for all gear shafts is reduced by the ISFD support.

(5) No significant difference was seen for vibration reduction of the driving shaft in cases when ISFD is installed on either the driving or driven shafts. However, for the driven shaft, vibration reduction was observed to be significantly better when ISFD is installed on the driven shaft.

\section{Conflicts of Interest}

There are no conflicts of interest regarding the publication of this paper. 


\section{Acknowledgments}

The work described in this paper was supported financially by 2015 Beijing Scientific Research and Graduate Training Project (0318-21510028008). This support is gratefully acknowledged.

\section{References}

[1] J. Zhou, W. Sun, and G. Liu, "Review of vibration and noise in gear reducer," Journal of Mechanical Transmission, vol. 38, no. 6, pp. 163-170, 2014 (Chinese).

[2] K. Ding, X. Zhu, and Y. Chen, "The vibration characteristics of typical gearbox faults and its diagnosis plan," Journal of Vibration and Shock, vol. 20, no. 3, pp. 7-12, 2001.

[3] G. Wang, P. Sun, and K. Fang, "A research on the reduction of vibration and noise of the gearbox by using damping alloys," Journal of Jiangsu University of Science and Technology (Natural Science Edition), vol. 8, no. 3, pp. 14-20, 1994.

[4] C. Gu and X. Wu, "Passive vibration damping technology of gear," Machinery Design \& Manufacture, vol. 9, pp. 74-76, 2010.

[5] Z. Youchen, Research on Vibration Reliability And Vibration Damping Strategy with Modification of Gears, Northeastern University, Shenyang, China, 2010.

[6] B. Mao, L. Lin, and T. Cao, "Study on reducing vibration and noise of the gear transmissions by using damped ring," Machine Design and Research, vol. 21, no. 1, pp. 47-49, 2005.

[7] Q.-Y. Wang, D.-Q. Cao, and J.-B. Yang, "Axial vibration reduction characteristics of a gear system with a damping ring," Journal of Vibration and Shock, vol. 32, no. 6, pp. 190-194, 2013.

[8] J. Vance, F. Zeidan, and B. Murphy, Machinery Vibration and Rotordynamics, John Wiley \& Sons, Inc, 2010.

[9] C.-S. Chen, S. Natsiavas, and H. D. Nelson, "Coupled lateraltorsional vibration of a gear-pair system supported by a squeeze film damper," Journal of Vibration and Acoustics, vol. 120, no. 4, pp. 860-867, 1998.

[10] C. Chen, S. Natsiavas, and H. D. Nelson, "Stability analysis and complex dynamics of a gear-pair system supported by a squeeze film damper," Journal of Vibration and Acoustics, vol. 119, no. 1, pp. 85-88, 1997.

[11] C.-W. Chang-Jian, "Bifurcation and chaos analysis of the porous squeeze film damper mounted gear-bearing system," Computers \& Mathematics with Applications, vol. 64, no. 5, pp. 798-812, 2012.

[12] B. Ertas, V. Cerny, J. Kim, and V. Polreich, "Stabilizing A 46 MW multi-stage utility steam turbine using integral squeeze film bearing support dampers," in Proceedings of the ASME Turbo Expo 2014: Turbine Technical Conference and Exposition (GT '14), Düsseldorf, Germany, June 2014.

[13] O. De Santiago and L. S. Andrés, "Dynamic response of a rotor-integral squeeze film damper to couple imbalances," in Proceedings of the ASME Turbo Expo 2000: Power for Land, Sea, and Air (GT '00), Munich, Germany, May 2000.

[14] S. Zhu, J. Lou, Q. He, and X. Weng, Vibration Theory and Vibration Isolation, National Defense Industry Press, 2006.

[15] O. C. De Santiago and L. A. San Andrés, "Imbalance response and damping force coefficients of a rotor supported on end sealed integral squeeze film dampers," in Proceedings of the ASME 1999 International Gas Turbine and Aeroengine Congress and Exhibition (GT '99), Indianapolis, IN, USA, June 1999.
[16] O. De Santiago, L. San Andrés, and J. Oliveras, "Imbalance response of a rotor supported on open-ends integral squeeze film dampers," Journal of Engineering for Gas Turbines and Power, vol. 121, no. 4, pp. 718-724, 1999.

[17] K. Ding, W. Li, and X. Zhu, Gears and Gearbox Fault Diagnosis Practical Technology, China Machine Press, 2005. 


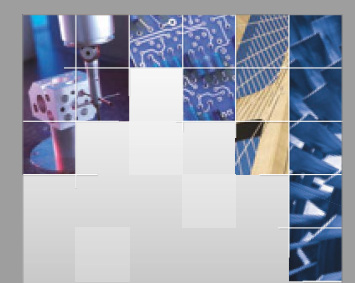

\section{Enfincering}
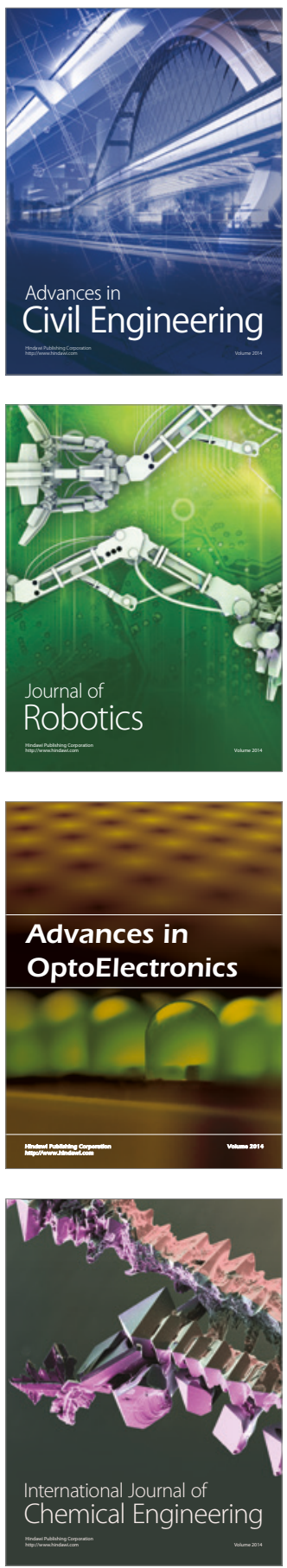

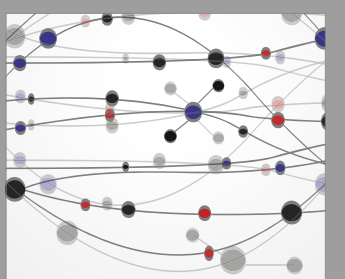

The Scientific World Journal

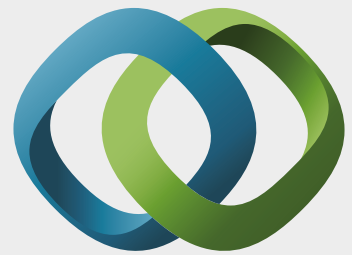

\section{Hindawi}

Submit your manuscripts at

https://www.hindawi.com
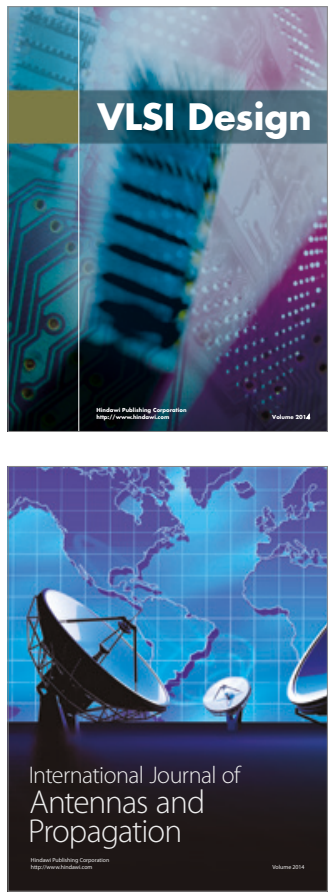

\section{Rotating}

Machinery
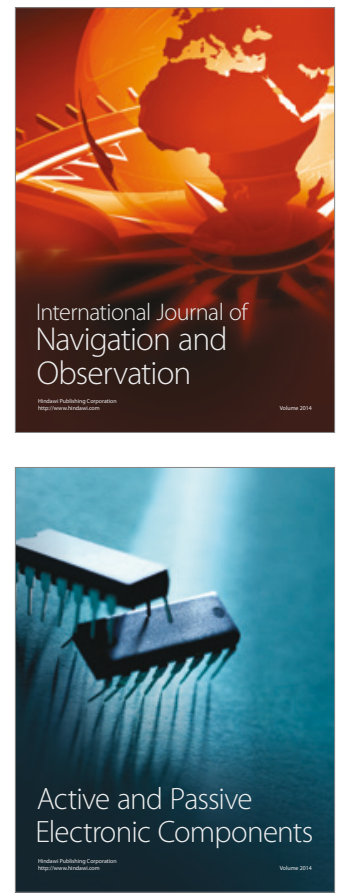
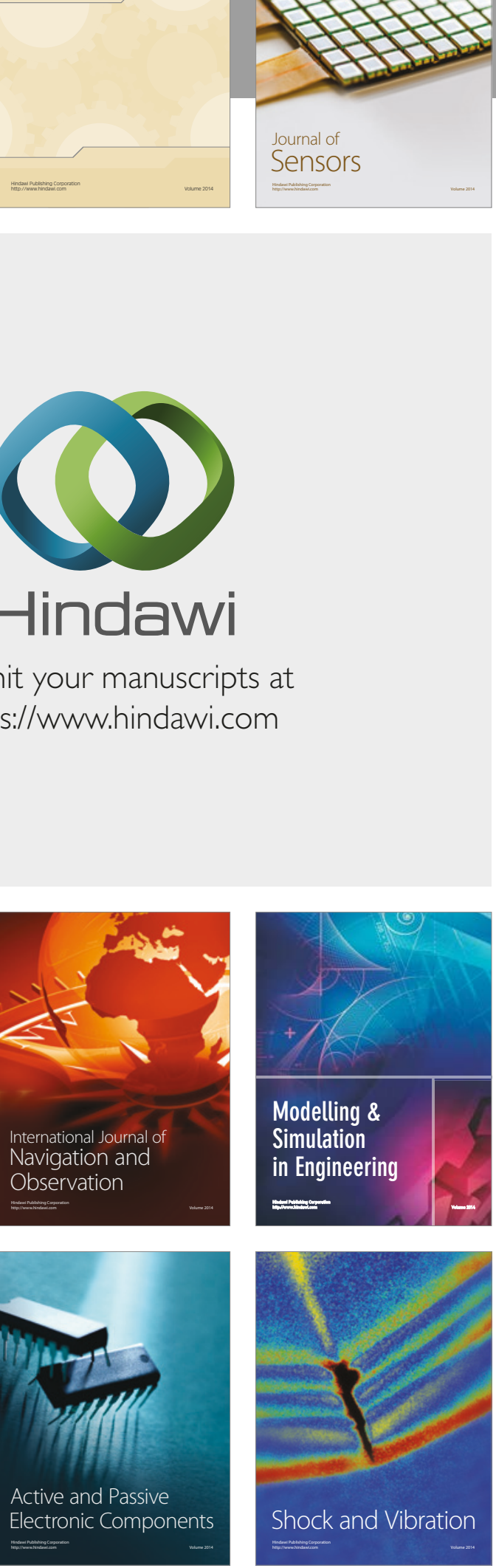
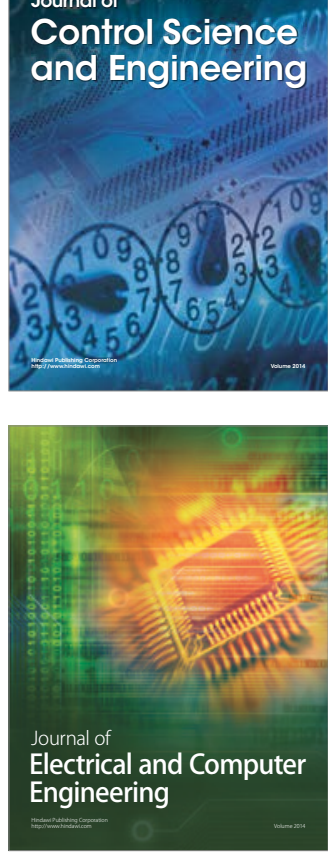

Distributed

Journal of

Control Science

and Engineering
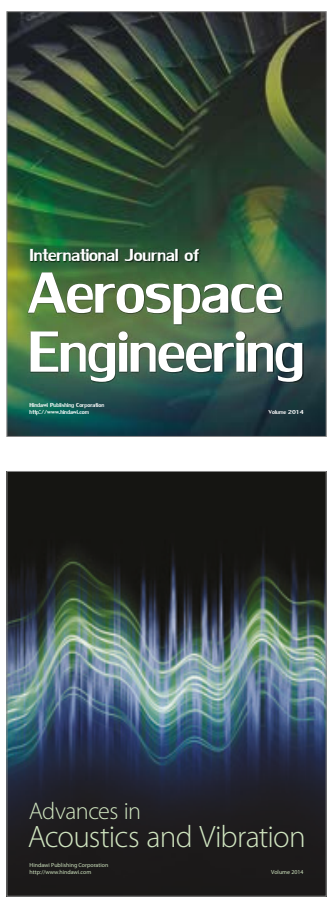

Sensor Networks 